\title{
Rio 2016: Os preparativos e desafios da cidade olímpica
}

\section{Rio 2016: The preparations and challenges of the olympic city}

\author{
William Cléber Domingues Silva (SILVA, W. C. D.) \\ Lluís Mundet i Cerdan (MUNDET, Ll.)
}

RESUMO - Esse trabalho tem por objetivo discutir e analisar o processo de preparação da cidade do Rio de Janeiro para a realização dos megaeventos esportivos que nela ocorrerão durante essa década. Leva-se em conta que tal discussão se torna plenamente justificável devido à complexidade desse processo e aos consideráveis recursos públicos e privados direcionados à execução desses megaeventos. A metodologia utilizada para a elaboração deste texto foi apoiada em revisão bibliográfica tendo sido consultados documentos oficiais, trabalhos acadêmicos, reportagens de jornais, dentre outros. Os resultados encontrados sugerem que os desafios a serem enfrentados pela sociedade brasileira durante a preparação para os megaeventos esportivos são bastante expressivos. No entanto, acredita-se que se for efetivada uma visão de longo prazo projetada mais particularmente no Dossiê de Candidatura dos Jogos Olímpicos e Paraolímpicos de 2016, acredita-se que o Brasil e a cidade do Rio de Janeiro poderão colher benefícios duradouros e com isso alcançar destaque no competitivo mercado internacional de eventos.

Palavras chave: Jogos Olímpicos; Preparativos; Rio 2016.

ABSTRACT - The aim of this paper is to discuss and analyze the preparation process of Rio de Janeiro as the host-city of mega sporting events during this decade. The process complexity and the amount of public and private money that will be invested in these mega events justify this discussion. A literature review was made by searching in official documents, scholarly articles, journals etc. The results suggest that the challenges which Brazil society will face during the preparation for the mega sporting events are very significant. However, if the long term strategy were accomplished for the 2016 Olympic and Paralympic games the city of Rio de Janeiro as the Projects showed, Brazil and Rio de Janeiro can have positives and durable benefits and then achieve prominence in the competitive international events market.

Key words: Olympic Games; Preparation; Rio 2016.

\footnotetext{
Formação: Graduação em Turismo (Bacharelado) pela Fundação Educacional São José - MG, Especialização em Administração Hoteleira - SENAC - MG, Mestrado em Turismo e Meio Ambiente UNA - BH. Doutorando em Turismo, Direito e Empresa, pela Universitat de Girona - Espanha. Atividade profissional: Professor Assistente do Curso de Turismo da Universidade Federal Rural do Rio de Janeiro. Endereço físico para correspondência: Rua Guararapes, 63/302. CEP: 36090-370 - Juiz de Fora - Minas Gerais (Brasil). Telefone: (32) 8415-5442. E-mail: williamwcds@yahoo.com.br.

** Formação: Licenciatura en Filosofía y Letras (Geografía) pela Universidad Autónoma de Barcelona (UAB), Master in Leisure and Tourism Studies pela Universidad de Gante (Flandes, Bélgica), Doctorado en Geografía pela Universidad de Girona (UdG). Atividade profissional: Profesor Titular da Facultad de Turismo da Universidad de Girona (UdG). Endereço físico para correspondência: Facultat de Turisme, Universitat de Girona, Plaça Ferrater Mora 1. CEP: 17071 - Girona - Catalunya (Espanya). Email: lluis.mundet@udg.cat.
} 


\section{INTRODUÇÃO}

A indicação da cidade do Rio de Janeiro como sede de grandes eventos esportivos no período de 2007 a 2016 sugere que os seus gestores estão buscando um posicionamento de destaque no disputado segmento de megaeventos internacionais.

Nesse cenário os gestores da capital fluminense ${ }^{1}$ utilizam-se de seus atrativos naturais, cultura popular e apoio institucional como argumentos para consolidá-la como um dos principais destinos do mundo para a realização de congressos, convenções e demais tipos de eventos internacionais, dentre eles os megaeventos esportivos.

Nesse artigo, tem-se uma discussão sobre o potencial, bem como, sobre as transformações que a cidade do Rio de Janeiro vem sofrendo para alcançar papel de destaque no acirrado mercado de eventos internacionais.

Para tal discussão se utilizou basicamente dois documentos: o Dossiê da Candidatura do Rio de Janeiro para os Jogos Olímpicos e Paraolímpicos de 2016 (2013) e o Plano de Legado da Cidade para a Copa 2014 e Jogos Olímpicos e Paraolímpicos (2013). Ao longo do texto foram traçadas comparações que demonstram que ambos possuem o mesmo direcionamento em relação às transformações pelas quais a cidade está passando.

Além disso, durante a exposição serão abordados temas e conceitos relacionados ao mercado do turismo de negócios e eventos no Rio de Janeiro, sobre a relação da cidade com os megaeventos esportivos, bem como sobre a sua preparação para sediar o maior e mais consagrado evento esportivo do planeta: Os Jogos Olímpicos (JO) de 2016.

\section{O TURISMO DE NEGÓCIOS E EVENTOS NO RIO DE JANEIRO}

Diferentes autores, como Mascarenhas (2011); Dacosta (2008); Neves Júnior e Silva (2010), comentam que a realização de eventos, proporciona diferentes impactos nas cidades ou países que os realizam.

\footnotetext{
${ }^{1}$ Fluminense é o nome dado às pessoas que nasceram no Estado do Rio de Janeiro. Carioca é o nome dado às pessoas nascidas na cidade do Rio de Janeiro. Capital fluminense é o nome dado à capital do Estado do Rio de Janeiro, ou seja, à cidade do Rio de Janeiro.
}

Turismo \& Sociedade (ISSN: 1983-5442). Curitiba, v. 7, n. 1, p. 99-117, janeiro de 2014. Dossiê sobre Megaeventos. 
Nesse sentido, observa-se que os responsáveis pelas cidades que captam diferentes tipos de eventos identificam que os mesmos colaboram para diminuir a sazonalidade, proporcionam mídia espontânea, ampliam a arrecadação de impostos, favorecem maior permanência dos turistas na localidade dentre outros impactos. (TENAN ${ }^{2}$ apud NEVES JÚNIOR; SILVA, 2010).

Roche (2000, p. 1), ao discutir essa temática, define megaeventos como:

Eventos de larga escala cultural (incluindo comerciais e esportivos) que têm uma característica dramática, apelo popular massivo e significância internacional. Eles são tipicamente organizados por combinações variáveis de governos nacionais e organizações internacionais não governamentais e ainda podem ser ditos como importantes elementos nas versões 'oficiais' da cultura pública.

Tal definição encontra aderência no atual contexto brasileiro e também da cidade do Rio de Janeiro, pois nos últimos anos, podem-se perceber por parte dos gestores públicos da cidade do Rio de Janeiro, consideráveis esforços na captação, organização e promoção dos mais variados tipos de eventos. Essa aderência pode estar baseada na estrutura já existente na capital fluminense, em suas singularidades turísticas e nos investimentos em promoção que estão sendo realizados através de diferentes entidades como, por exemplo, o Instituto Brasileiro de Turismo (EMBRATUR), o Rio Convention and Visitors Bureau (Rio C\&VB) e também por outras agências como a Associação Brasileira de Centros de Convenções e Feiras (ABRACEF) e a Associação Brasileira das Empresas de Eventos (ABEOC) (NEVES JÚNIOR; SILVA, 2010, p. 9).

Dados publicados pela ABEOC (2012) demonstram que no ano de 2011, Buenos Aires, ficou em primeiro lugar como cidade que mais realizou eventos internacionais na América Latina, num total de noventa e quatro, o Rio de Janeiro assumiu a liderança no Brasil se configurando em segundo lugar na América Latina com a realização de sessenta e nove eventos internacionais em 2011, São Paulo apareceu na terceira posição ao realizar sessenta eventos internacionais nesse mesmo período.

A concorrência no mercado de eventos e negócios é acirrada e os mercados estão se expandindo e mudando constantemente, seja nacionalmente ou internacionalmente. Nesse cenário, novos destinos surgem, enquanto outros se reinventam para entrar na disputa por um mercado de concorrência internacional. Percebe-se haver uma tendência

\footnotetext{
${ }^{2}$ TENAN, I. P. S. Eventos. 2. ed. São Paulo: Aleph, 2000.
} 
na preservação dos atrativos naturais e culturais para criar o desenvolvimento de uma herança passível de ser acessada tanto por moradores quanto por turistas. Sendo assim, existem diversos destinos que redescobriram seu passado e tiraram proveito disso, e a cidade do Rio de Janeiro é uma delas (KOTLER, 2007).

Nesse contexto, o turismo de eventos assume um papel fundamental na composição de atrações de uma cidade. Diante desse cenário repleto de oportunidades de negócios, a cidade do Rio de Janeiro firma-se no país como o principal destino internacional de eventos, superando a cidade de São Paulo (ABEOC, 2012).

Para Neves Júnior e Silva (2010), a cidade do Rio de Janeiro, possui instalações para eventos bem localizadas e equipadas, uma gama de hotéis distribuídos pela orla, uma gastronomia diversificada, dentre outros aspectos de interesse o que possibilita ao destino ser caracterizado como um centro cultural e social do Brasil. Complementando o raciocínio os autores esclarecerem que o Réveillon e o Carnaval identificam o Rio de Janeiro no cenário local e global o que favorece a expansão dos negócios e a divulgação dos vários atrativos espalhados pela cidade, com destaque para o Cristo Redentor, eleito uma das sete novas maravilhas do mundo (FOLHA ONLINE, 2013).

Apesar da primeira colocação da cidade para sediar eventos no Brasil e de já ter sediado eventos como a ECO 92 e o Pan-Americano 2007, considera-se que os gestores do Rio ainda possuem grandes desafios a serem vencidos na preparação da cidade para sediar eventos, principalmente megaeventos esportivos como a Copa do Mundo de Futebol da FIFA (Federation Internationale de Football Association) em 2014 e os Jogos Olímpicos em 2016.

Portanto, essa busca por grandes eventos cria uma competição com outras cidades e no Rio de Janeiro isso não está sendo diferente. Os espaços destinados a esses eventos são insuficientes, e a necessidade de construção e adequação da infraestrutura é latente (NEVES JÚNIOR; SILVA, 2010). A corrida para construir, reformar e modernizar os locais para os eventos se acelera.

Essa sucessão de eventos na área desportiva permite que muitas das obras realizadas para um determinado evento sejam aproveitadas para outros grandes acontecimentos. Especialmente as obras ligadas a infraestrutura urbana e de acesso como metrôs, arenas esportivas, corredores de ônibus, estacionamentos, aeroviária, portos, segurança, saneamento e saúde (NEVES JÚNIOR; SILVA, 2010). 
Sendo assim e ao se analisar as colocações de Urani, (2009, p. 5-6) pode-se perceber que o turismo junto com o setor de serviços são grandes fontes geradoras de recursos do estado, depois da indústria petroquímica.

Para tanto, o Governo Federal com o Programa de Aceleração do Crescimento (PAC) previu investimentos da ordem de $\mathrm{R} \$ 4$ bilhões no Rio de Janeiro, incluindo três eixos: logística - rodoviária, ferroviária, portuária, hidroviária e aeroportuária; energética - geração e transmissão de energia elétrica, petróleo, gás natural e energias renováveis; e social e urbana - Programa Luz para Todos, saneamento, habitação, metrôs, recursos hídricos (URANI, 2009, p. 5-6).

Com isso, surge a oportunidade de a cidade despontar na área de eventos no Brasil e no Mundo, bastando, para isto, realizar as mudanças necessárias com qualidade e discernimento para o longo prazo. Cabe no momento que antecede a esses eventos, recomendar um exaustivo diálogo entre o poder público, o meio acadêmico, a iniciativa privada e a população local, para que os resultados sejam promissores e se configurem em benefícios e legados duradouros para a cidade (NEVES JÚNIOR; SILVA, 2010).

Como se pode constatar a cidade do Rio de Janeiro vem se posicionando no mercado internacional como um dos principais polos receptores de eventos internacionais no mundo. Acredita-se que essa estratégia tem por objetivo construir uma nova imagem da cidade e do país no exterior. Devido a tal estratégia, a cidade foi apresentada como candidata aos principais eventos esportivos do planeta, destacando-se os Jogos Olímpicos e Paraolímpicos de 2016, a Copa do Mundo de Futebol da FIFA de 2014, a Copa das Confederações de 2013, os Jogos Mundiais Militares de 2011, tendo como referência preliminar o fato de ter realizado os Jogos Pan-americanos de 2007.

Segundo Miagusko (2011, p. 12), os Jogos Pan-americanos de 2007 serviram como embrião da futura conquista para sediar as Olimpíadas de 2016, apesar do relativo sucesso na organização do evento, surgiram questionamentos em relação aos altos custos do projeto e também a respeito da subutilização dos equipamentos esportivos após a sua realização.

Ilustrando tal situação, podem-se apresentar os relatos de Mascarenhas (2011, p. 51) que ao fazer a análise dos impactos gerados com a organização do Pan 2007, conclui que: 
Os gastos com o evento correspondem a uma preocupação social, numa cidade cujos recursos públicos destinados a setores fundamentais, como saúde, saneamento e educação, encontram-se muito aquém das necessidades básicas da população. A respeito, cumpre registrar que o orçamento original do Pan - 2007 girava em torno de 260 milhões de dólares. Essa cifra foi subindo progressivamente, não obstante a constante revisão dos planos, reduzindo as pretensões iniciais. No final de 2005, estimava-se um gasto pelo menos quatro vezes maior do que o inicialmente previsto. E muito pouco se investiu no esporte em si (apenas 7\% do gasto municipal para o evento), na formação de talentos, de forma que os atletas reivindicaram mais atenção e investimento. Por fim os jogos alcançaram o custo total de 3,7 bilhões de reais, aproximadamente oito vezes maior do que o montante inicialmente previsto.

Complementando, Miagusko (2011, p. 12) ao tecer comentários sobre a organização dos Jogos Pan-americanos de 2007 no Rio de Janeiro, argumenta que:

Transparece é que o principal legado dos Jogos Pan-americanos (sic) foi ter qualificado a candidatura olímpica e garantido a vitória do Rio de Janeiro como cidade sede. Em relação ao legado urbanístico e social há uma controvérsia muito maior sobre seus resultados não apenas do ponto de vista da utilização dos recursos, da construção dos equipamentos, mas, sobretudo, do conjunto de intervenções urbanísticas relacionadas às populações socialmente mais vulneráveis e à legislação urbana que tem o paradigma da emergência e da suspensão de determinados dispositivos legais como princípio ordenador.

Diante de tais questionamentos sugere-se que nos preparativos para a Copa do Mundo de Futebol da FIFA 2014 e para as Olimpíadas e Paraolimpíadas de 2016 as questões relacionadas ao controle dos orçamentos das obras sejam bem coordenadas pelos gestores envolvidos com o processo e também pelo Tribunal de Contas da União (TCU) e pelo Ministério Público.

A indicação para ser sede de eventos internacionais e de megaeventos esportivos traz grandes desafios de gestão para uma cidade sede e para os demais atores envolvidos com o processo de execução dos projetos. A organização de eventos desse porte faz com que as autoridades competentes assumam compromissos consideráveis com instituições internacionais que controlam o esporte mundial como o Comitê Olímpico Internacional (COI) e a Federação Internacional de Futebol Associado (FIFA).

Devido aos compromissos assumidos com tais entidades, COI, FIFA, dentre outras, com a limitação dos prazos impostos por elas e pela complexidade, por exemplo, do caderno de intenções que descreve o projeto olímpico, pode-se notar que a cidade do Rio de Janeiro está se preparando para os Jogos Olímpicos de 2016 por meio de um 
"estado de emergência" onde ferramentas operacionais questionáveis como o Regime Diferenciado de Contratações (RDC) estão sendo introduzidas na preparação dos eventos Copa do Mundo de Futebol da FIFA 2014 e os Jogos Olímpicos de 2016. (MIAGUSKO, 2011, p. 12).

O mesmo autor, baseando-se em Oliveira $(2011)^{3}$ e Vainer $(2011)^{4}$, alerta sobre os riscos da adoção de tais mecanismos na organização dos megaeventos esportivos a serem realizados no país, observando que:

Há um conjunto de instrumentos, dispositivos e leis que tem suspendido outros dispositivos legais e que são aprovados sob o argumento da emergência. No âmbito federal, há o Ato Olímpico e uma MP que criou a Autoridade Olímpica (APO). Além disso, tramita no Congresso outra MP 521 que institui o Regime Diferenciado de Contratações e estabelece mecanismos legais que suspendem a Lei de Licitações (8.666/93), que visa criar "regras especiais" para as licitações tanto na Copa quanto nas Olimpíadas. Este dispositivo tem sido muito criticado pela imprensa, órgãos de controle e demais setores da sociedade que apontam uma violação da lei de licitações e falta de transparência nos processos licitatórios, com o sigilo prévio sobre o orçamento, centralização no COI e na FIFA dos aditamentos de contrato. No âmbito municipal há três pacotes de leis acompanhados de alguns decretos como o Projeto Porto Maravilha (1999), o Plano de Estruturação das Vargens (1999) e o Pacote Olímpico (OLIVEIRA, 2011). A aprovação dessas leis mostra um traço comum: "regras especiais" e suspensão dos dispositivos legais anteriores que na prática tem tornado o Rio de Janeiro uma "cidade da exceção" (VAINER, 2011).

Apesar disso ou devido a isso, se percebe na cidade relevantes intervenções em sua infraestrutura urbana. Ao abordar o assunto, a revista "ISTO É" (2011) em sua versão online publicou os seguintes comentários a respeito dos preparativos da cidade para os megaeventos esportivos que estão por vir:

O Rio é uma cidade em transformação! Uma sucessão de construções começa a modificar substancialmente sua cara, sem tirar seu charme. No centro e na Barra da Tijuca, nova fronteira do metrô, prédios inteligentes e luxuosos brotam. Também na área menos rica da cidade, a zona norte, há muitos edifícios residenciais sendo erguidos, além de megaobras de infraestrutura. Dezenas de novos hotéis estão sendo construídos ou passam por reforma, como o tradicional Hotel Glória. Tantas intervenções urbanas misturam à paisagem tapumes e obras pontuais que, ao final, descortinarão um Rio diferente, que aparece nos radares de instituições respeitadas em todo mundo (ISTO É, 2011).

\footnotetext{
${ }^{3}$ OLIVEIRA, N. G. de. Força de lei: rupturas e realinhamentos institucionais na busca do "sonho olímpico" carioca. XIV ENCONTRO NACIONAL DA ANPUR. Rio de Janeiro: ANPUR, 2011.

${ }^{4}$ VAINER, C. Cidade de exceção: reflexões a partir do Rio de Janeiro. XIV ENCONTRO NACIONAL DA ANPUR. Rio de Janeiro: ANPUR, 2011.
} 
Os motivos que levam um país/cidade a se candidatar a ser sede de megaeventos esportivos não são muito claros. No caso brasileiro, acredita-se que os principais motivos sejam aqueles relacionados à recuperação do atraso econômico e social de seu povo, à necessidade de modernização de equipamentos urbanos, à recuperação e revitalização de áreas até então não dominadas pelo Estado como as áreas de domínio do tráfico de drogas, à dinamização de diferentes setores econômicos, e, sobretudo à projeção-consolidação de uma nova imagem da cidade/país no cenário internacional.

De acordo com a Organização para Cooperação e Desenvolvimento Econômico (OCDE, 2008) em publicação online, se conclui que o que motiva muitos países a se candidatarem como sedes de megaeventos esportivos é a possibilidade de desenvolvimento de longo prazo. Para essa instituição o acirramento das disputas entre as cidades candidatas tem ocorrido pelo fato das economias emergentes terem alcançado maior projeção econômica e internacional nos últimos anos. Menciona que nesse contexto é natural que países como China, Brasil, África do Sul, Rússia, Coréia do Sul, queiram se projetar internacionalmente através da captação e promoção de megaeventos esportivos (OCDE, 2008).

Pelo fato de o Rio de Janeiro ainda estar se preparando para a organização dos Jogos, não se sabe a imagem que a cidade e o país conseguirão passar para o restante do mundo, contudo estudos como o de Giambiagi et al, (2010) sugerem que um bom caminho a ser seguido seria o de vincular a imagem/marca da cidade à questão da sustentabilidade ambiental, o que poderia contribuir para transmitir a imagem da localidade de capital ambiental do planeta.

No mesmo estudo, os pesquisadores destacam que tal empreitada exigiria investimentos e intervenções específicas em questões relacionadas à água, ao ar e ao solo. Como exemplos de tais intervenções se podem citar a despoluição de lagoas e rios nas diversas regiões da cidade, a redução dos níveis de emissão de dióxido de carbono $\left(\mathrm{CO}_{2}\right)$ e ainda o plantio de milhões de árvores por todas as regiões do município e a construção de novas moradias para a população que ainda não possui residência própria (GIAMBIAGI et al, 2010). 


\section{O DOSSIE DA CANDIDATURA RIO 2016: A CIDADE E OS PREPARATIVOS PARA OS JOGOS OLÍMPICOS}

O Dossiê da Candidatura do Rio de Janeiro para as Olimpíadas e Paraolimpíadas de 2016, formalizado em 2009 é um documento oficial que contou com o apoio e participação de diferentes representantes da comunidade olímpica e paraolímpica além dos três níveis de governo brasileiro (federal, estadual e municipal) durante a sua elaboração (DOSSIÊ DE CANDIDATURA RIO 2016, 2013). Esse Dossiê de Candidatura do Rio de Janeiro descreve de maneira ordenada o planejamento de longo prazo que a cidade deverá seguir durante a sua preparação para os Jogos Olímpicos e Paraolímpicos de 2016.

De acordo com o Dossiê de Candidatura, a motivação principal para a organização dos Jogos Olímpicos de 2016 no Rio de Janeiro, é a "celebração e a transformação da cidade", além da possibilidade de unir o poder de interação dos esportes olímpicos e paraolímpicos ao espírito festivo do carioca, com o objetivo de conseguir benefícios duradouros para a cidade, para o país e para os movimentos olímpico e paraolímpico (DOSSIÊ DE CANDIDATURA RIO 2016, 2013).

No dossiê também consta que o planejamento das ações relacionadas aos Jogos Olímpicos, o Comitê de Candidatura Rio 2016, que é o órgão responsável pela coordenação e implementação do projeto olímpico brasileiro, identificou 5 estratégias necessárias à concretização da visão de celebração e transformação que a cidade/país quer passar aos participantes dos jogos e ao mundo. Ainda, que as estratégias adotadas são as seguintes: Participação dos jovens, uma transformação social através do esporte, uma liderança esportiva regional, promoção global e uma entrega de sucesso. Para alcançar os resultados esperados com a organização do evento, no Dossiê de Candidatura Rio 2016 (2013) se estipula um planejamento de longo prazo que extrapola o período de realização dos Jogos.

Nesse sentido observa-se que as maiores preocupações para com a cidade estão relacionadas com o legado olímpico que deverá ficar no município e durar por décadas. Pensando nisso e visando benéficos duradouros para a cidade, no Dossiê de Candidatura Rio 2016 (2013), se contemplou a implantação de um Comitê de Legado Olímpico e também um Comitê de Legado Urbano. 
De acordo com o Dossiê de Candidatura Rio 2016 (2013), o Plano Mestre dos Jogos Olímpicos e Paraolímpicos de 2016, garantirá à cidade a modernização de sua infraestrutura de transporte e das novas instalações esportivas, possibilitará a revitalização da sua decadente região portuária e ainda oportunizará consideráveis intervenções no setor ambiental e de segurança pública.

Ao se aprofundar na análise do Dossiê de Candidatura Rio 2016 (2013), pode-se notar que o conceito geral do evento, está alicerçado em quatro pilares principais: Excelência técnica; uma experiência memorável; transformação e apoio aos movimentos Olímpico e Paraolímpico. No quadro 1 abaixo, se ilustra essa informação:

QUADRO 1 - OS QUATRO PILARES DOS JOGOS OLÍMPICOS RIO 2016

\begin{tabular}{|c|c|c|c|}
\hline $\begin{array}{l}\text { EXCELÊNCIA } \\
\text { TÉCNICA }\end{array}$ & $\begin{array}{l}\text { UMA EXPERIÊNCIA } \\
\text { MEMORÁVEL }\end{array}$ & TRANSFORMAÇÃO & $\begin{array}{l}\text { APOIO AOS } \\
\text { MOVIMENTOS } \\
\text { OLÍMPICO E } \\
\text { PARAOLÍMPICO }\end{array}$ \\
\hline $\begin{array}{l}\text { Plano Mestre e } \\
\text { instalações dos Jogos }\end{array}$ & Parceria com os clientes & Modernização do porto & $\begin{array}{l}\text { Integração da juventude } \\
\text { e lives site. }\end{array}$ \\
\hline $\begin{array}{l}\text { Vila Olímpica e } \\
\text { paraolímpica }\end{array}$ & Estádios cheios & $\begin{array}{l}\text { Inserção social - jogos } \\
\text { integrados à sociedade }\end{array}$ & $\begin{array}{l}\text { Desenvolvimento } \\
\text { esportivo na América } \\
\text { do Sul e além }\end{array}$ \\
\hline Acomodações & $\begin{array}{l}\text { Apresentações } \\
\text { esportivas }\end{array}$ & $\begin{array}{l}\text { Desenvolvimento } \\
\text { sustentável em longo } \\
\text { prazo }\end{array}$ & $\begin{array}{l}\text { Impacto das marcas } \\
\text { olímpica e paraolímpica }\end{array}$ \\
\hline Transportes & - & - & - \\
\hline Segurança & - & - & - \\
\hline Garantia Financeira & - & - & - \\
\hline
\end{tabular}

FONTE: DOSSIÊ DA CANDIDATURA RIO 2016 (2013).

No documento de Candidatura consta que visando o desenvolvimento de longo prazo da cidade e do estado do Rio de Janeiro, o Comitê de Candidatura Rio 2016 alinhou-se aos três níveis de governo no momento do planejamento e escolha dos locais onde ocorrerão as competições olímpicas (DOSSIÊ DE CANDIDATURA RIO 2016, 2013). 
No dossiê também se tem que durante esse processo foi instituído pelo governo municipal o Comitê de Legado Urbano da cidade, tendo esse comitê como principal função se certificar que as obras propostas para os Jogos Olímpicos de 2016 estejam alinhadas com o plano estratégico da cidade.

Nesse aspecto, torna-se relevante destacar que todas as competições dos Jogos ocorrerão nos limites do município da cidade do Rio de Janeiro. Ao verificar sobre a abrangência da proposta contida no Dossiê de Candidatura, pode-se conhecer as principais características das 4 regiões da cidade/município que sofrerão intervenções para a realização dos Jogos Olímpicos de 2016, conforme segue abaixo:

a) Barra da Tijuca: expansão e conectividade

A região da Barra da Tijuca estará recebendo importantes investimentos na área de mobilidade urbana. Dentre tais investimentos, destacam-se aqueles direcionados à expansão do metrô, à criação da transoeste e da transcarioca, dentre outras intervenções que supostamente contribuirão consideravelmente com a melhoria da qualidade de vida dos moradores da região. Projetam-se também investimentos na melhoria habitacional e proteção ambiental com a despoluição das lagoas da região. Mascarenhas, Bienenstein e Sánchez (2011) destacam que a Barra da Tijuca é uma parte da cidade em franca expansão imobiliária. Nesse sentido alertam que muitos recursos financeiros durante a preparação para os jogos estão direcionados para essa região. Os autores observam que tais investimentos podem privilegiar os interesses de alguns grupos hegemônicos em detrimento de outros de cunho social.

b) Deodoro: juventude

De acordo com o Dossiê de Candidatura Rio 2016 (2013), a região de Deodoro já havia recebido investimentos públicos e intervenções em equipamentos urbanos durante a preparação do Rio de Janeiro para a realização dos jogos Pan-americanos de 2007, constando no dossiê que essa área é a região da cidade com o maior percentual de jovens.

Turismo \& Sociedade (ISSN: 1983-5442). Curitiba, v. 7, n. 1, p. 99-117, janeiro de 2014. Dossiê sobre Megaeventos. 
Os Jogos Pan-americanos de 2007 favoreceram a ampliação da prática de esportes por parte dessa população que com o projeto olímpico estará recebendo também o Parque Radical projetado para reforçar as possibilidades de prática de esportes e melhoria da qualidade de vida dos moradores do bairro (DOSSIE DE CANDIDATURA RIO 2016, 2013).

c) Maracanã: renovação urbana

Essa é uma região próxima ao centro da cidade, do sambódromo e do complexo esportivo do Maracanã. Local projetado para ser a sede da final da Copa do Mundo de Futebol da FIFA de 2014 e das cerimônias de abertura e encerramento dos Jogos Olímpicos de 2016 (DOSSIÊ DE CANDIDATURA RIO 2016, 2013).

De acordo com o projeto olímpico da cidade, a região passará por importantes intervenções urbanas, destacando-se a revitalização total da sua zona portuária, que deverá ser transformada em uma região turística.

\section{d) Copacabana}

Consta no dossiê que Copacabana é considerada uma região turística da cidade onde predomina grande densidade populacional paralelamente a poucas possibilidades de crescimento (DOSSIÊ DE CANDIDATURA RIO 2016, 2013).

No documento consta também, que a região é procurada por turistas de diferentes partes do Brasil e do exterior e que apesar de oferecer uma boa estrutura de serviços ainda carece de investimentos, destacando-se, no entanto aqueles direcionados à parte ambiental (DOSSIÊ DE CANDIDATURA RIO 2016, 2013).

Pensando em sanar tal carência, no Projeto Olímpico da cidade se prevê iniciativas relacionadas à limpeza das águas do bairro e outras ações ambientalmente corretas.

Os Jogos Olímpicos de 2016 estão desencadeando uma série de políticas públicas que irão vincular a educação ao esporte. Para isso, consta no dossiê que o Comitê de Candidatura Rio 2016 irá desenvolver, por exemplo, um programa pedagógico em escolas discutindo temas variados de esportes, essa iniciativa tendo 
como objetivo relacionar práticas esportivas a um estilo de vida saudável (DOSSIÊ DE CANDIDATURA RIO 2016, 2013).

No Dossiê de Candidatura também se estipula que no Projeto Olímpico da cidade se disponibiliza organizar os Jogos Olímpicos com características sustentáveis. Além disso, que a proposta brasileira se apoiará nas belezas naturais da cidade durante o processo de planejamento e execução do evento.

Nesse sentido, no dossiê consta que o Comitê Organizador da Candidatura formalizou um acordo com a Comissão Especial do Meio Ambiente que faz parte do Comitê da Candidatura Rio 2016 (DOSSIÊ DE CANDIDATURA RIO 2016, 2013).

Por meio do acordo firmado a Comissão Especial do Meio ambiente passa a atuar como uma Divisão Olímpica para a Sustentabilidade (DOS) que é uma agência subordinada a Autoridade Pública Olímpica (APO). Desta forma, destaca-se que Divisão Olímpica para a Sustentabilidade terá por finalidade coordenar todos os projetos e investimentos previstos no programa de preservação do meio ambiente desenvolvido pela cidade e para os jogos olímpicos (DOSSIÊ DE CANDIDATURA RIO 2016, 2013).

Por fim, ressalta-se que o Programa de Sustentabilidade dos Jogos Olímpicos e Paraolímpicos de 2016 a ser realizado no Rio de Janeiro irá contemplar as seguintes áreas: Conservação da água, energia renovável, jogos neutros em carbono e gestão do lixo e responsabilidade social (DOSSIÊ DE CANDIDATURA RIO 2016, 2013).

Já o Plano de Legado da cidade do Rio de Janeiro para a Copa Do Mundo de Futebol da FIFA 2014 e para os Jogos Olímpicos de 2016 é uma proposta de planejamento da prefeitura da cidade para garantir o legado previsto com a realização dos grandes eventos esportivos que estão por acontecer na cidade (PLANO DE LEGADO DA CIDADE PARA A COPA 2014 E JOGOS OLÍMPICOS E PARAOLÍMPICOS 2016, 2013). Nesse ambiente de grandes investimentos e intervenções em diferentes regiões da cidade, consta que os especialistas da prefeitura, através do Plano de Legado para a Copa, Olimpíadas e Paraolimpíadas, dividiram o legado dos grandes eventos em quatro grandes áreas complementares: Meio ambiente, transportes, infraestrutura e desenvolvimento social. 
Na parte ambiental, no Plano de Legado se destaca que uma das principais intervenções a realizar será a de recuperação das lagoas da região, sendo que tal medida poderá beneficiar plenamente os moradores da cidade com medidas nessa direção.

Projeta-se, através do Plano até 2016, o plantio de aproximadamente 24 milhões de árvores no estado, visando garantir a proteção de áreas ambientais e incentivar o replantio de espécies nativas da mata atlântica.

Estima-se ainda no Plano de Legado da cidade que a rede cicloviária será expandida em 150 quilômetros, tal medida se efetivada irá duplicar as ciclovias da cidade o que provocará impactos positivos no trânsito, na qualidade de vida das pessoas e na diminuição da emissão de gases tóxicos.

Indo na mesma direção, o Dossiê de Candidatura Rio 2016 (2013), projeta que os Jogos Olímpicos de 2016, serão Jogos neutros em emissão de carbono, pois as emissões geradas pela ocorrência dos Jogos serão compensadas com o plantio de 3 milhões de árvores na cidade do Rio de Janeiro e até 24 milhões de árvores no estado até 2016.

Também se espera que a área social seja beneficiada com o legado deixado pelos Jogos Olímpicos Rio 2016, pois, de acordo com o Plano de Legado da cidade até 2020 será feita a urbanização de todas as favelas do Rio de Janeiro, possibilitando a recuperação de comunidades carentes e o incremento de importantes serviços públicos até então inexistentes em muitas dessas comunidades.

Outra medida que consta no Plano de Legado e que já vem sendo adotada na área social é a construção e legalização de moradias populares. Essa ação visa atingir 100 mil unidades o com isso reduzir o déficit habitacional do estado e ao mesmo tempo aumentar os níveis de segurança das moradias e dos moradores da cidade.

No Plano de Legado da cidade do Rio de Janeiro se projeta universalizar a prática de esportes na rede pública de ensino. Essa iniciativa se consolidada certamente representará um grande legado para os moradores da cidade. Espera-se ainda a consolidação da universalização do ensino de inglês na rede municipal de ensino.

De acordo com Plano de Legado da cidade e indo na mesma direção do Dossiê de Candidatura Rio 2016 (2013), os principais projetos urbanísticos a serem desenvolvidos pela cidade nos próximos anos são: a revitalização da região portuária da cidade através do projeto Porto Maravilha, a revitalização dos entornos do Maracanã, do 
sambódromo do Rio de Janeiro, do estádio do Engenhão e do Parque Olímpico da cidade, além de plano de ações para o setor hoteleiro e construção da Vila Olímpica.

Ao analisar as intervenções que estão sendo realizadas na região portuária da cidade do Rio de Janeiro, o jornal O Globo em sua versão online confirmou a execução de obras previstas no Dossiê de Candidatura Rio 2016 e no Plano de Legado da cidade, pois:

Foi inaugurado, pouco depois das $20 \mathrm{~h}$ desta sexta-feira $\left(1^{\circ}\right)$, o Museu de Arte do Rio (MAR), na Praça Mauá, no dia em a cidade completou 448 anos. O complexo é a primeira obra cultural pronta do projeto de revitalização da Zona Portuária e a abertura conta a presença da presidente Dilma Rousseff e da ministra da Cultura Marta Suplicy, além do prefeito Eduardo Paes e do governador Sérgio Cabral (G1, 01/03/2013).

Esta obra do museu retrata a primeira grande inauguração desde o início das obras na região portuária da cidade. O MAR como já é conhecido objetiva contar a história da cidade através da arte e contará com mostras temporárias, exposições e acervo permanente.

Em outra reportagem, essa do caderno Rio 2016 do jornal O GLOBO, Alfredo Lopes, presidente da Associação Brasileira da Indústria Hoteleira (ABIH) alerta para o risco da expansão do parque hoteleiro carioca por meio de lançamentos viabilizados por meio de cotas de investidores (O GLOBO, 2013).

Na parte de transportes e mobilidade urbana, no Plano de Legado da cidade se projeta a implantação de um novo sistema intermodal de transportes. Esse sistema possibilitará a integração entre os corredores de ônibus expressos (BRTs - Bus Rapid Transit) a trens, barcas e metrô. Com as intervenções na parte de mobilidade urbana projeta-se que nos próximos anos a utilização do transporte de alta capacidade no Rio de Janeiro passe de 16\% para 50\% (DOSSIÊ DE CANDIDATURA RIO 2016, 2013).

Se tais projeções forem confirmadas acredita-se que a qualidade de vida do carioca será muito positivamente impactada, já que atualmente observam-se congestionamentos em várias regiões da cidade em diferentes horários do dia.

De acordo com o planejamento dos gestores da cidade, os principais projetos na área de transportes são as construções das vias expressas que serão alimentadas por BRTs, sendo elas a transcarioca, a transoeste, a transolímpica, a transbrasil e a conexão Zona Sul - Barra (O GLOBO, 2013). 
$\mathrm{Na}$ ilustração abaixo se demonstra a proposta de integração entre as novas vias expressas que em alguns casos já estão sendo construídas:

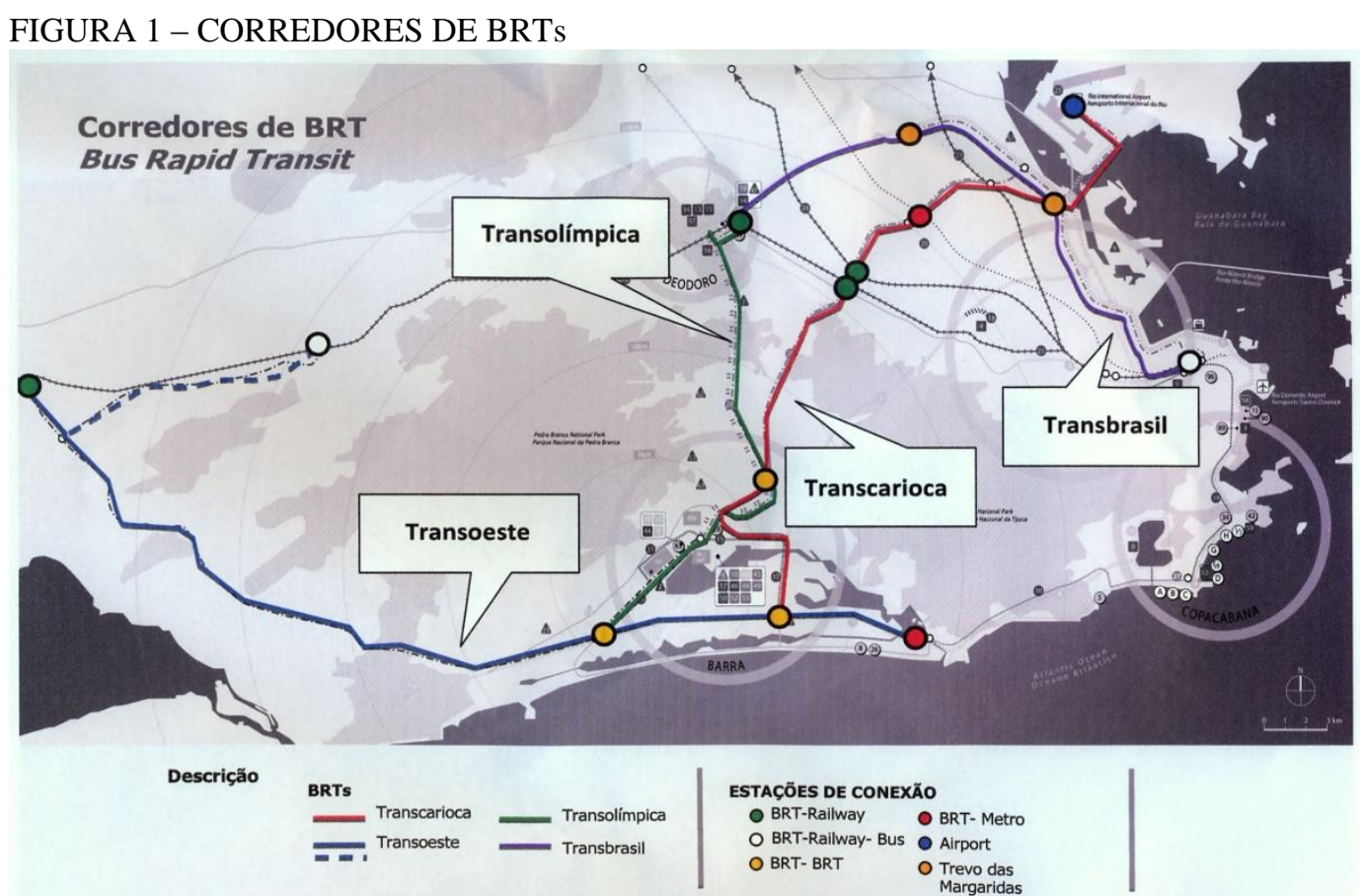

FONTE: PLANO DE LEGADO DA CIDADE DO RIO DE JANEIRO PARA A COPA DE 2014 E OLIMPÍADAS DE 2016, s. d.

Pode-se notar que os desafios a serem enfrentados pelos gestores da cidade do Rio de Janeiro na sua preparação para os megaeventos esportivos não são pequenos. Diante de tais desafios, recomenda-se que ocorra um intenso monitoramento por parte da sociedade civil organizada, das autoridades competentes e dos órgãos de controle no que tange a execução das obras e controle do orçamento.

\section{CONSIDERAÇÕES FINAIS}

Com a realização dos megaeventos esportivos Copa do Mundo de Futebol da FIFA 2014 e dos Jogos Olímpicos 2016 no Brasil, as discussões em torno do tema se acentuam. Nesse ambiente de realização e preparação acredita-se que diferentes olhares e contribuições são fundamentais para se encontrar o melhor modelo a seguir.

Diante do que foi exposto, nota-se que a cidade do Rio de Janeiro atravessa um novo momento em sua história, pois a oportunidade de sediar os principais eventos 
esportivos do planeta exige e exigirá um grande esforço dos seus gestores e de toda sociedade brasileira, contudo, acredita-se que por meio de suas instituições, da capacidade técnica e administrativa dos responsáveis em realizar tais empreitadas e pela efetiva coordenação política durante a preparação para os Jogos Olímpicos e Copa do Mundo FIFA 2014, o Rio de Janeiro deverá promover com qualidade os eventos que se disponibilizou a sediar.

Paralelamente a isso é relevante destacar a ocorrência de questionamentos feitos por boa parte da população brasileira em relação aos aspectos positivos e negativos de promover megaeventos esportivos no Brasil.

Tais questionamentos juntamente com outras demandas provocaram e ainda estão provocando uma série de manifestações populares por diferentes regiões do país. Tais protestos vistos pelo Brasil a partir do segundo semestre de 2013 sugerem aos gestores públicos, à classe política e a toda sociedade brasileira um maior zelo para com os gastos públicos, uma maior participação da sociedade em torno das discussões e decisões tomadas durante o processo de candidatura e realização de megaeventos esportivos e ainda a efetiva necessidade de transparência no controle e na divulgação dos gastos públicos necessários à realização desses acontecimentos que provocam desafios e oportunidades duradouras para as cidades sedes.

\section{REFERÊNCIAS}

ABEOC. Associação Brasileira das Empresas de Eventos. Clipping do Setor: Top 10 do ranking ICCA por país e cidades das Américas e do Brasil. Disponível em: <http://www.abeoc.org.br/2012/05/\%E2\%80\%9Ctop-10\%E2\%80\%9D-do-ranking-iccapor-pais-e-cidades-das-americas-e-do-brasil/>. Acesso em: 15/05/2013.

DACOSTA, L. CORREA, D. RIZZUTI, E. VILLANO, B. MIRAGAYA, A. Legados de Megaeventos Esportivos. Brasília: Ministério do Esporte, 2008.

DOSSIÊ DA CANDIDATURA do Rio de Janeiro para os Jogos Olímpicos e Paraolímpicos de 2016. Comissão de Organização dos Jogos olímpicos do Rio de Janeiro. Disponível em: <http://www.rio2016.org.br/pt/Default.aspx>. Acesso em: 20/03/2013. 
EMBRATUR. Indicadores de turismo. Brasília: EMBRATUR, maio/2000. Disponível em: <http://www.copa2014.org.br/noticias/Noticia.aspx?noticia=296>. Acesso em: 26/10/2013.

FOLHA ONLINE, 2013. Cristo redentor é eleito uma das sete novas maravilhas do mundo. Disponível em: <http://www1.folha.uol.com.br/ilustrada/2007/07/310220cristo-redentor-e-eleito-uma-das-sete-novas-maravilhas-do-mundo.shtml >. Acesso em: $13 / 10 / 2013$.

GIAMBIAGI, F.; FERREIRA, S. G.; VIANNA, S. B; SOUTO; L. A. O papel do Estado, o projeto olímpico e a importância do legado. XXII FÓRUM NACIONAL PROGRAMA NACIONAL DE DIREITOS HUMANOS. E NOVOS TEMAS. Páginas 1-43, Rio de Janeiro 2010. Disponível em: http://www.inae.org.br/pub/ep/EP0361.pdf. Acesso em: 10/11/2013.

JORNAL O GLOBO. Mutante que vive um sonho olímpico. Caderno Rio 2016, página $11.09 / 11 / 2013$.

KOTLER, P. Marketing no Setor Público. São Paulo: Bookman Companhia, 2007.

MASCARENHAS, G. O ideário urbanístico em torno do olimpismo: Barcelona (1992) e Rio de Janeiro (2007). In: O jogo continua: megaeventos esportivos e cidades. MASCARENHAS, G.; BIENENSTEIN, G.; SÁNCHEZ, F. Rio de Janeiro: EdUERJ, 2011, p. 41-56.

MIAGUSKO, E. "Antes da copa, depois do pan: Impactos sociais e renovação urbana no Rio de Janeiro". ANAIS XI CONGRESSO LUSO AFRO BRASILEIRO DE CIÊNCIAS SOCIAIS - DIVERSIDADES E DESIGUALDADES, 07 a 10/08/2011 UFBA, SALVADOR - BA. Disponível em:

<http://www.xiconlab.eventos.dype.com.br/resources/anais/3/1314387476_ARQUIVO_ AntesdaCopaedepoisdoPan-impactossociaiserenovacaourbananoRiodeJaneiro.pdf $>$.

Acesso em: 10/11/2013.

NEVES JÚNIOR, F. G. S; SILVA, W. C. D. Turismo de Negócios e Eventos no Rio de Janeiro: Uma análise introdutória. XI ENCONTRO NACIONAL DE TURISMO COM BASE LOCAL. Anais... Universidade Federal Fluminense - Niterói, 2010.

NOGUEIRA, C; MAGALHÃES, L.E; SCHMIDT, S. in Jornal O Globo. Metrópole: Em jogo, a transformação do Rio. Caderno Rio 2016, página 10, 09/11/2013.

ORGANIZAÇÃO PARA COOPERAÇÃO E DESENVOLVIMENTO ECONÔMICO, (OCDE), 2008. Local development benefits from staging major events. ISBN 97892-6404206-3, Barcelona.

PLANO DE LEGADO DA CIDADE PARA A COPA 2014 E JOGOS OLÍMPICOS E PARAOLÍMPICOS. Disponível em: 
<http://www.google.com.br/search?q=PLANO+DE+LEGADO+DA+CIDADE+PARA $+\mathrm{A}+\mathrm{COPA}+2014+\mathrm{E}+\mathrm{JOGOS}+\mathrm{OL} \% \mathrm{C} 3 \% 8 \mathrm{DMPICOS}+\mathrm{E}+\mathrm{PARAOL} \% \mathrm{C} 3 \% 8 \mathrm{DMPICOS}$ $\% 2 C \& h l=p t-B R>$. Acesso em: 06/11/2013.

PORTO, H; TORRES, L. In: G1 Rio, 2013. Museu de Arte do Rio é inaugurado. Disponível em: <http://g1.globo.com/rio-de-janeiro/noticia/2013/03/museu-de-arte-dorio-e-inaugurado.html>. Acesso em: 10/11/2013.

REVISTA, ISTO É. (2011). Rio: uma cidade em transformação. Edição 2169, junho/2011. Disponível em:

<http://www.istoe.com.br/reportagens/140274_RIO+UMA+CIDADE+EM+TRANSFO RMACAO>. Acesso em: 15/11/2013.

SEBRAE, DF. Estudo de Mercado do Setor de Turismo de Eventos e Negócios do Distrito Federal. Brasília: SEBRAE, 2005.

ROCHE, M. Mega-events and modernity: Olympics and expos in the growth of global culture. London: Routledge, 2000.

URANI, A. Jornal dos Economistas. Salto Qualitativo na Retomada do Desenvolvimento. Dezembro de 2009, n. 245, p.5-6. Disponível em: <http://www.corecon-rj.org.br/pdf/JE_dezembro2009.pdf>. Acesso em: 12/11/2013.

ZANELlA, L. C. Manual de organização de eventos: planejamento e operacionalização. 2. Ed. São Paulo: Atlas, 2004.

Recebido em: 26-11-2013.

Aprovado em: 26-11-2013.

Turismo \& Sociedade (ISSN: 1983-5442). Curitiba, v. 7, n. 1, p. 99-117, janeiro de 2014. Dossiê sobre Megaeventos. 